\title{
Cultivation and biogeochemical analyses reveal insights into methanogenesis in deep subseafloor sediment at a biogenic gas hydrate site
}

\author{
Taiki Katayama (iD ${ }^{1}$, Hideyoshi Yoshioka (iD) ${ }^{1 凶}$, Masanori Kaneko ${ }^{1}$, Miki Amo ${ }^{2}$, Tetsuya Fujii ${ }^{2,5}$, Hiroshi A. Takahashi ${ }^{3}$ \\ Satoshi Yoshida ${ }^{4,6}$ and Susumu Sakata ${ }^{1}$
}

(C) The Author(s) 2021

\begin{abstract}
Gas hydrates deposited in subseafloor sediments are considered to primarily consist of biogenic methane. However, little evidence for the occurrence of living methanogens in subseafloor sediments has been provided. This study investigated viable methanogen diversity, population, physiology and potential activity in hydrate-bearing sediments (1-307 m below the seafloor) from the eastern Nankai Trough. Radiotracer experiments, the quantification of coenzyme F430 and molecular sequencing analysis indicated the occurrence of potential methanogenic activity and living methanogens in the sediments and the predominance of hydrogenotrophic methanogens followed by methylotrophic methanogens. Ten isolates and nine representative culture clones of hydrogenotrophic, methylotrophic and acetoclastic methanogens were obtained from the batch incubation of sediments and accounted for $0.5-76 \%$ of the total methanogenic sequences directly recovered from each sediment. The hydrogenotrophic methanogen isolates of Methanocalculus and Methanoculleus that dominated the sediment methanogen communities produced methane at temperatures from 4 to $55^{\circ} \mathrm{C}$, with an abrupt decline in the methane production rate at temperatures above $40{ }^{\circ} \mathrm{C}$, which is consistent with the depth profiles of potential methanogenic activity in the Nankai Trough sediments in this and previous studies. Our results reveal the previously overlooked phylogenetic and metabolic diversity of living methanogens, including methylotrophic methanogenesis.
\end{abstract}

The ISME Journal (2022) 16:1464-1472; https://doi.org/10.1038/s41396-021-01175-7

\section{INTRODUCTION}

Natural gas hydrates are cage-like structures of water molecules that contain low-molecular-weight gases, such as methane, and occur in subseafloor sediments along continental margins [1]. Previous geochemical studies suggest that gas hydrates primarily consist of biogenic methane $[2,3]$, which indicates that methanogenesis is an essential component of the biogeochemical cycle in deep subseafloor environments.

Extensive studies have been performed to characterize the methanogenic activity and diversity in sediments at gas hydrate sites using various biogeochemical techniques. Radiotracer-based activity measurements have revealed potential methanogenesis in sediments at the Cascadia Margin [4, 5], the Nankai Trough [6, 7] and the Blake Ridge [8]. Environmental molecular sequencing has been performed to identify the microbial taxa responsible for methanogenesis. However, previous studies often failed to recover the gene sequences of methanogens from sediments at hydrate sites [9-12], possibly due to the small proportions $(0.1 \%)$ of archaeal communities [13, 14]. In cultivation-based approaches, only a few methanogens have been successfully cultured from sediments at hydrate sites: novel species of Methanoculleus
$[15,16]$ and Methanococcus [17] and enrichment cultures containing the gene sequences of methanogens [12]. Determinations of living methanogens, population, diversity, physiology and ecology, and their depth-related profiles are fundamental for understanding biogenic gas hydrate formation, but such studies are still in their infancy. In particular, the potential for methylotrophic methanogenesis remains elusive in the deep subseafloor sediments, although its occurrence and contribution to biogenic methane formation have previously been suggested in the deep terrestrial subsurface [18-20]. The concentrations of methylotrophic substrates such as methanol in sediment core samples are generally low [21], which hampers potential activity measurement using a radiotracer.

The Nankai Trough is a convergent margin with widespread bottom-simulating reflectors (BSRs); hence, a substantial amount of gas hydrates may be present [22]. In this area, the methane in the gas hydrates is of biogenic origin according to its light carbon isotopic composition $\left({ }^{13} \mathrm{C} /{ }^{12} \mathrm{C}\right)$ and the predominance of methane over ethane and propane [23]. We previously recovered the $16 \mathrm{~S}$ rRNA and methyl-coenzyme $M$ reductase (MCR) gene sequences assigned to methanogenic archaea from sediments on Daini

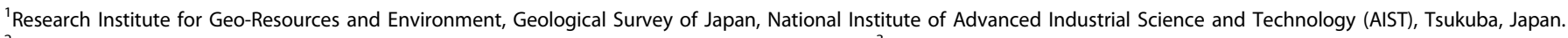

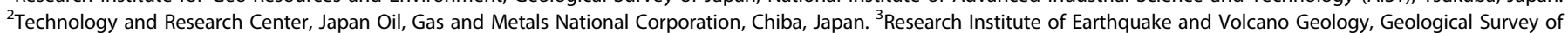

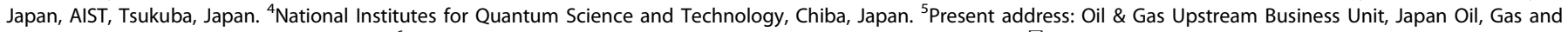
Metals National Corporation, Tokyo, Japan. ${ }^{6}$ Present address: Institute for Environmental Sciences, Aomori, Japan. ${ }^{\varpi}$ email: hi-yoshioka@aist.go.jp
} 
Atsumi Knoll in the eastern Nankai Trough, in which up to $80 \%$ of pore spaces in sandy turbidite sediments were filled with gas hydrates [24]. In addition, polar sn-2-hydroxyarchaeol, which is indicative of methanogens, was detected at depths down to the BSR at this site [25].

To expand our understanding of methanogenesis in the deep biosphere, we examined methanogen diversity, population and potential activity in the sediments acquired from Daini Atsumi Knoll. Radiotracer experiments were conducted to measure the potential activities of hydrogenotrophic, acetoclastic and methylotrophic methanogenesis in the sediment slurry samples. Coenzyme F430 was quantified to estimate the living methanogen biomass. Amplicon pyrosequencing of archaeal 16S rRNA genes was used to observe the diversity of methanogens. The long-term batch incubation of the sediments with various methanogenic substrates was also performed to obtain and physiologically characterize the viable methanogens.

\section{METHODS}

\section{Site description and sample collection}

Sediment core samples were collected from two boreholes, designated AT1-GT1 and AT1-C, in Daini Atsumi Knoll $\left(33^{\circ} 56^{\prime} \mathrm{N}, 137^{\circ} 19^{\prime} \mathrm{E}\right)$, a ridge between the forearc basin and the accretionary prism; the sediments covered the flank of the knoll. Gas hydrate-bearing strata in this area belong to the Ogasa Group, which was deposited in the middle to late Pleistocene [26]. Highly resistive anomalies in the logging data revealed an extensive gas hydrate-bearing zone distributed at 271-330 mbsf (referred to as the concentrated hydrate zone) and above the BSR (Fig. 1) [27]. The water depths of boreholes AT1-GT1 and AT1-C were 997 and $999 \mathrm{~m}$ below mean sea level, respectively. The distance between the two boreholes was less than $50 \mathrm{~m}$. Based on the measured temperatures in the monitoring wells in the AT1 area [28], the temperatures were $3{ }^{\circ} \mathrm{C}$ at the surface of the sediments and $14^{\circ} \mathrm{C}$ at the depth corresponding to the BSR (330 mbsf). The core samples were collected from shallow overburden sediments above the concentrated hydrate zone (above $273 \mathrm{mbsf}$ ) of borehole
AT1-GT1 in February 2011 and from the concentrated hydrate zone (259-307 mbsf) of borehole AT1-C in June-July 2012. The upper layer at this site consists of clay rich slump sediment, which is considered to be a submarine landslide deposit that was transported from the top of the knoll, whereas the lower unit consists of turbidites, with alternating sand and mud sediment, originating as eroded debris that was transported by rivers and deposited in deep marine environments via turbidity currents (Fig. 1a) [26].

\section{Geochemical analysis}

The stable carbon isotope ratios of methane were measured using a Finnigan DELTA plus XP isotope-ratio mass spectrometer (IR-MS) equipped with a Hewlett Packard 5890 gas chromatograph (GC) and a ThermoQuest combustion interface (Thermo Fisher Scientific, Waltham, MA, USA). The dissolved inorganic carbon (DIC) was measured using a DELTA V Advantage IR-MS equipped with a gas chromatography-based GasBench II system (Thermo Fisher Scientific).

The porewater was squeezed from the subcore samples using an automatic hydraulic press (AUTOFOUR/30: Carver, Inc., Summit, NJ). After the water chemistry was measured on board, the water samples were stored at $-80^{\circ} \mathrm{C}$ until further processing in the laboratory. The acetate concentration in the porewater sample was measured using a Prominence HPLC system (Shimadzu Co. Ltd., Kyoto, Japan) equipped with an electrical conductivity detector. The concentrations of methylated compounds, methanol, dimethyl sulfide and trimethylamine (TMA) in the porewater sample were measured using GC/MS (Agilent 5973, Agilent Technologies, Santa Clara, CA, USA) equipped with a headspace sampler (Agilent 7697A, Agilent Technologies).

\section{Methanogenic activity measurement using a radiotracer}

The methane production rates were measured using radiotracer experiments as previously described $[5,6]$. Samples were taken from the centre of the sediment core and mixed at a 1:2 volume ratio with artificial sulfatefree seawater containing $28.4 \mathrm{~g} \mathrm{I}^{-1} \mathrm{NaCl}, 5.7 \mathrm{~g} \mathrm{I}^{-1} \mathrm{MgCl}_{2} \cdot 6 \mathrm{H}_{2} \mathrm{O}, 0.7 \mathrm{~g} \mathrm{I}^{-1} \mathrm{KCl}$, $0.09 \mathrm{gl}^{-1} \mathrm{KBr}$ and $1 \mu \mathrm{gl}^{-1}$ resazurin in an anaerobic chamber [24]. Prior to mixing, the artificial seawater was purged with oxygen-free $\mathrm{N}_{2} / \mathrm{CO}_{2}$ gas $(80: 20, v / v)$ and autoclaved. Forty millilitres of the slurry sample was dispensed in a 100-ml serum vial sealed with a butyl rubber stopper and

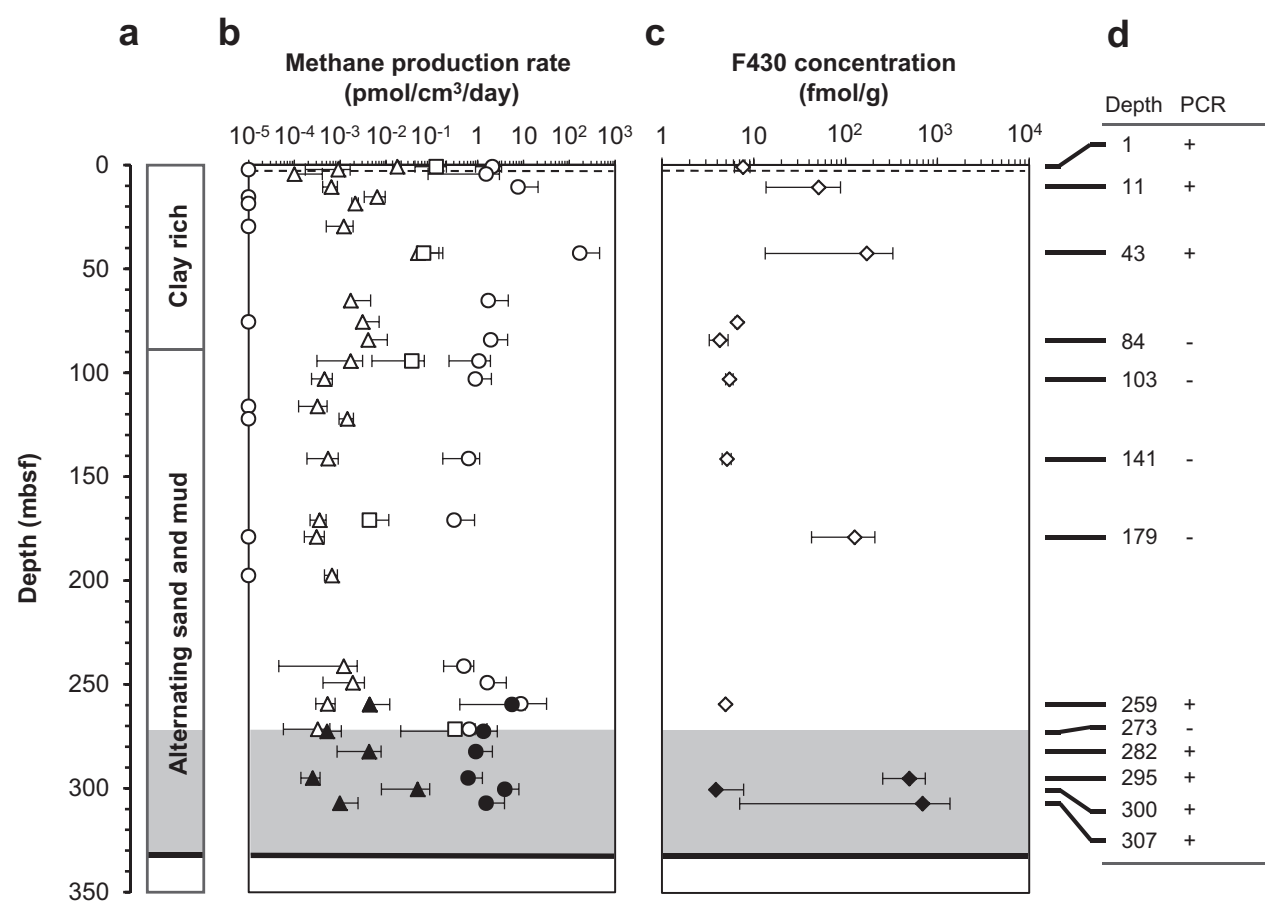

Fig. 1 Potential for methanogenesis in the studied sites. Depth profiles of the AT1-GT1 (open symbols) and AT1-C (solid symbols) boreholes showing the sedimentary facies (a), methane production rates via hydrogenotrophic (circle), acetoclastic (triangle) and methylotrophic (square) pathways (b), F430 concentrations (c) and PCR amplification results of archaeal 16S rRNA genes [The presence (+) and absence (-) of PCR products] (d). Methane production rates below the detection limits are indicated as $10^{-5}$ pmol per $\mathrm{cm}^{3}$ per day for convenience. Error bars represent a standard deviation of triplicate (b) or duplicate (c) analysis. The SMTZ (sulfate-methane transition zone; broken line), hydrateconcentrated zone (shaded area) and BSR (bottom-simulating reflector; bold line) are indicated in the figure. 
aluminium crimp. The radiotracer ${ }^{14} \mathrm{C}$-bicarbonate $(10 \mu \mathrm{l}, 199 \mathrm{kBq}),\left[2-{ }^{14} \mathrm{C}\right]-$ acetate $(10 \mu \mathrm{l}, 42 \mathrm{kBq})$ or ${ }^{14} \mathrm{C}$-methanol $(10 \mu \mathrm{l}, 114 \mathrm{kBq})$ was then injected into the vial. The vials were incubated at $9^{\circ} \mathrm{C}$ to approximate the in situ temperature under an atmosphere of $\mathrm{N}_{2} / \mathrm{CO}_{2}(80: 20, \mathrm{v} / \mathrm{v})$ without shaking for 14,28 and 42 days.

After incubation, the reactions were terminated with the addition of $1 \mathrm{M}$ $\mathrm{NaOH}$. The produced ${ }^{14} \mathrm{CH}_{4}$ was oxidized to ${ }^{14} \mathrm{CO}_{2}$ by flushing the bottle headspace with $\mathrm{He}$ through a furnace containing $\mathrm{CuO} .{ }^{14} \mathrm{CO}_{2}$ was collected in vials containing 2-phenethylamine and mixed with a 10-ml Permafluor $\mathrm{E}^{+}$scintillation cocktail (Perkin Elmer, Waltham, MA, USA). The total ${ }^{14} \mathrm{C}$ activities were determined in triplicate for each incubation period with a Tri-Carb 3100TR liquid scintillation counter (Perkin Elmer). The ${ }^{14} \mathrm{C}$ activity at zero time was used as a control. The methane production rate was calculated using the equation $a_{p} /\left(a_{r} \cdot t\right) \cdot \psi \cdot C$, where $a_{p}$ and $a_{r}$ are the activities of the product and the added reactant (i.e., $\mathrm{CO}_{2}$, acetate or methanol), respectively; $t$ is the incubation period; $\psi$ is the porosity of the sediments; and $C$ is the in situ concentration of the reactant. The alkalinity in the porewater sample was previously measured [24].

\section{Extraction and quantification of coenzyme F430}

The coenzyme F430 in sediment samples was extracted and quantified with the modified methods of Kaneko et al. [29]. In method 1, the sediment core samples that were stored at $<-25^{\circ} \mathrm{C}$ were extracted with $1 \%$ formic acid $(\mathrm{pH} 2)$ by ultrasonication on ice, followed by centrifugation to recover the supernatant. This step was repeated three times. The supernatant was introduced to an anion exchange column ( $Q$ Sepharose column; GE Healthcare, Tokyo, Japan) that had been equilibrated with $50 \mathrm{mM}$ Tris/ $\mathrm{HCl}$ $\mathrm{(pH} 7.5)$ and washed with deionized water prior to use. The recovered eluent was introduced to a $\mathrm{C}_{18}$ SPE column (Sep-Pack; Waters Corp. Milford, MA, USA) that had been washed with methanol and conditioned with $1 \%$ formic acid. The F430 fraction on the column was eluted with $100 \%$ methanol. The $\mathrm{F} 430$ fraction was dried and reacted with $\mathrm{BF}_{3} /$ methanol to convert F430 to its pentamethyl ester (F430M). In method 2, all treatments before methyl esterification were conducted without glassware, and liquid-liquid extraction with $\mathrm{H}_{2} \mathrm{O}$ and dichloromethane was conducted before methyl esterification to remove lipids. The F430M obtained by both methods was quantified using an LC-MS/MS (Agilent 6490 triple quadpole LC-MS coupled with an Agilent 1260 LC system). The concentration of F430 was calculated by an external standard method using the concentration of the known coenzyme F430 standard, which had been prepared using methanogenic granules as previously described [30].

\section{4-Pyrosequencing of archaeal 16S rRNA genes from sediment core samples}

The DNA extracted from the sediment core samples in this study for the archaeal 16S rRNA gene analyses was the same as that in Katayama et al. [24] for the prokaryotic 16S rRNA and mcrA gene analysis.

The $\mathrm{V} 3$ and $\mathrm{V} 4$ regions of the archaeal $16 \mathrm{~S}$ rRNA genes were amplified with AmpliTaq Gold 360 DNA polymerase (Thermo Fisher Scientific) using the Arc806R primer fused with 454-specific adaptor A and 6-bp barcode sequences and the Arc109F primer fused with adaptor B. The primers used in this study are listed in Supplementary Table S1. No amplicons were obtained from the $84,103,141,179$ and 273 mbsf samples. The cycling conditions were $95^{\circ} \mathrm{C}$ for $10 \mathrm{~min}$, followed by $35-40$ cycles of $95^{\circ} \mathrm{C}$ for $30 \mathrm{~s}, 50^{\circ} \mathrm{C}$ for $30 \mathrm{~s}$ and $72^{\circ} \mathrm{C}$ for $60 \mathrm{~s}$, and a final extension period of $7 \mathrm{~min}$ at $72^{\circ} \mathrm{C}$. Under this condition, the PCR product from the no-template control was not observed in agarose gel electrophoresis. Six replicates of the PCR products for each sample were pooled and purified using a MonoFas DNA purification kit (GL Sciences, Tokyo, Japan). Pyrosequencing was performed using a 454 Life Sciences GS FLX Titanium platform (Roche, Basel, Switzerland) at Hokkaido System Science Co., Ltd. (Sapporo, Japan).

\section{Enrichment culture and isolation of methanogens}

The sediment slurry (prepared as described above) was dispensed in 40-ml aliquots into a $100-\mathrm{ml}$ serum vial sealed with a butyl rubber stopper and an aluminium crimp under an atmosphere of $\mathrm{N}_{2} / \mathrm{CO}_{2}(80: 20, \mathrm{v} / \mathrm{v})$. The slurry sample was supplemented with either $\mathrm{H}_{2} / \mathrm{CO}_{2}(80: 20 ; 0.1 \mathrm{MPa})$ plus $10 \mathrm{mM}$ acetate or $10 \mathrm{mM}$ methanol plus $10 \mathrm{mM}$ TMA. To prevent the growth of bacteria that compete with methanogens (i.e., acetogenic bacteria), a slurry sample supplemented with the respective methanogenic substrates and bacteria-specific antibiotics, i.e., kanamycin and vancomycin $\left(50 \mu \mathrm{m} \mathrm{ml}^{-1}\right.$ each), was also prepared. The vials were incubated at $9^{\circ} \mathrm{C}$ without shaking. The sediment slurry sample from $43 \mathrm{mbsf}$ was also cultured without methanogenic substrates at 9 and $25^{\circ} \mathrm{C}$. The time courses of methane production and hydrogen consumption were measured via GC with a thermal conductivity detector.

The methane-producing cultures were subsequently transferred to a sulfate-free saline mineral medium (WS medium) [31] supplemented with either $\mathrm{H}_{2} / \mathrm{CO}_{2}(80: 20 ; 0.1 \mathrm{MPa})$ plus $2 \mathrm{mM}$ acetate, $20 \mathrm{mM}$ acetate or $10 \mathrm{mM}$ methanol plus $10 \mathrm{mM}$ TMA. Titanium(III) citrate $(0.2 \mathrm{mM})$ and 2-mercaptoethane sulfonic acid $(5 \mathrm{mM})$ were also added to the medium. Cultivation was performed at $25^{\circ} \mathrm{C}$ under an atmosphere of $\mathrm{N}_{2} / \mathrm{CO}_{2}$. After the methane production was terminated, $5 \mathrm{ml}$ of the methane-producing cultures, including initial enrichment cultures as described above, were harvested and used for the clone library analysis as described below.

A deep agar slant method combined with a dilution-to-extinction method [31] was used to isolate the methanogens. The antibiotics, kanamycin and vancomycin, were added to the media at concentrations of $50 \mathrm{~g} \mathrm{ml}^{-1}$ each. The purity of the isolate was verified by microscopic observation and 16S rRNA gene amplification and sequencing.

Strains $1 \mathrm{H} 1 \mathrm{Hc7}, 25 \mathrm{XMC2}$ and MSS35 were deposited in the Japan Collection of Microorganisms (JCM) under JCM numbers JCM 39199, JCM 39200 and JCM 39201, respectively.

\section{Sanger sequencing from methanogenic enrichment cultures and isolates}

Total DNA was extracted from the enrichment cultures and isolates using an ISOIL and ISOPLANT II DNA extraction kit (NIPPON GENE, Tokyo, Japan), respectively, and according to the manufacturer's protocol. The archaeal and bacterial 16S rRNA genes were amplified from enrichment cultures using the primer pairs Arc21F and Univ1490R and Bac8F and Bac1492R, respectively. The products were purified using a MonoFas DNA purification kit, cloned into the PCR4-TOPO vector (Thermo Fisher Scientific) and sequenced using the dideoxynucleotide chain termination method with BigDye terminator reagents (Thermo Fisher Scientific).

The 16S rRNA and mcrA gene sequences of methanogenic isolates were determined. The ME3MFe and ME2 $r^{\prime}$ primer pair was used for mcrA gene amplification. The bacterial $16 \mathrm{~S}$ rRNA gene was amplified using the primer pair Bac8F and Bac1492R to check the purity of the methanogenic isolate.

\section{Sequence analysis}

The 454-pyrosequencing reads were analyzed using Mothur ver. 44 [32] as previously described [20] with the following modifications. Each unique operational taxonomic unit (OTU) was classified by a Bayesian classifier and on the Silva taxonomy SSU Ref NR99 release 138 datasets [33] with a confidence threshold of $80 \%$. The taxonomic information of the OTUs ( $>99 \%$ sequence similarity) was obtained from the majority consensus taxonomy of the sequences within the OTU with a consensus confidence threshold of $80 \%$. The known methanogens were retrieved from this majority consensus taxonomy for the OTUs of the 16S rRNA gene sequences. OTU clustering (>99\%) was also performed using pyrosequencing reads and sequences of methanogenic culture clones and isolates to examine whether the sequences of culturable methanogens were also detected in the original sediment core samples.

The representative 16S rRNA gene sequences of methanogenic culture clones and isolates were aligned with their relatives. Neighbour-joining and maximum-likelihood trees were constructed using MEGA v.6 [34] and TREEFINDER [35], respectively.

The GenBank/EMBL/DDBJ accession numbers of the 16S rRNA gene sequences were LC183829 to LC183864. The 454 sequences were deposited in the DDBJ Sequence Read Archive database under accession number DRA005478.

\section{Cultivation of methanogenic isolates at different temperatures}

Strains $1 \mathrm{H} 1 \mathrm{Hc} 7$ and $25 \mathrm{XMc} 2$ were cultured using WS medium amended with $20 \mathrm{mM}$ formate, $4 \mathrm{mM}$ acetate, $0.2 \mathrm{mM}$ titanium III citrate and $5 \mathrm{mM}$ 2-mercaptoethane sulfonic acid at $4,9,20,25,30,40,45,55$ and $65^{\circ} \mathrm{C}$. The time course of methane production was measured in triplicate.

\section{RESULTS}

\section{Geochemistry of gas and porewater}

The stable carbon isotopic ratios of methane $\left(\delta^{13} \mathrm{C}_{-}-\mathrm{CH}_{4}\right)$ in the studied sediments ranged from -82.4 to $-61.1 \%$ o (Supplementary 
Table S2), suggesting their origin to be biogenic [36]. In addition, they were lower than those of DIC $\left(\delta^{13} \mathrm{C}\right.$-DIC) by an average of $-73 \%$ (Supplementary Table S2), a value consistent with the carbon isotope fractionation associated with hydrogenotrophic methanogenesis [36]. We, therefore, conclude that the methane in the sediments was biologically produced primarily via the carbonate reduction pathway.

The methanol concentrations in porewater samples were successfully determined, ranging from 6.7 to $75.6 \mu \mathrm{mol}$ (Supplementary Table S3), and permitted the estimation of methylotrophic methanogenic activity rates at 1, 43, 94, 171 and 271 mbsf, as described below. The methanol concentrations were comparable with those in shallow sediments from the Japan Sea (shallower than $30 \mathrm{mbsf}$ ) [21]. Dimethyl sulfide and TMA, which can also be used in general by methylotrophic methanogens, were below the detection limits $(<20 \mathrm{nM})$.

\section{Potential methanogenic activity rates}

The ${ }^{14} \mathrm{C}$ tracer experiments detected the potential activity of hydrogenotrophic methanogenesis in most sediments (21 out of 30) from the near-surface to the BSR (Fig. 1b), with activity rates ranging from 0.31 to $170 \mathrm{pmol} \mathrm{cm}^{-3} \mathrm{~d}^{-1}$. All nine sediment samples with activity rates below the detection limit were situated shallower than 200 mbsf. The potential methanogenic rates were comparable with those observed on Cascadia margin [4, 5]. The potential activities of methylotrophic and acetoclastic methanogenesis were also detected, ranging up to 0.12 and $0.049 \mathrm{pmol}$ $\mathrm{cm}^{-3} \mathrm{~d}^{-1}$, respectively. Relatively high rates observed via the hydrogenotrophic pathway are consistent with the carbon isotope fractionation between methane and DIC, as well as the methanogenic community composition (see below).

\section{Distribution of coenzyme F430}

F430 is a key prosthetic group of MCR that catalyses the last step of methanogenesis and the first step of methane oxidation [37]. Therefore, it is generally derived from both methanogens and anaerobic methanotrophic archaea (ANME) [38, 39]. A relevant point to be noted is that methanogens can only produce methane, while ANME may perform not only methane oxidation but also methane production [40, 41]. In this study, however, F430 detected in the sediment might be derived mostly from methanogens because the mcrA gene sequences obtained from the same DNA samples indicated the predominance of methanogens over ANMEs [24]. Due to the unstable nature of F430, the compound would not remain intact in the environment $[38,39]$. We, therefore, consider that most of the F430 detected in this study is a living biomarker of methanogens. In all 13 sediment samples analyzed F430 was successfully detected with a concentration ranging from 3.9 to $689 \mathrm{fmol}$ per $\mathrm{g}$ sediments (Fig. 1c). The predominant peaks of F430 concentration were observed in the 43, 179, 295 and 307 mbsf samples. This depth profile was roughly consistent with those of potential methanogenic activity rates (Fig. $1 \mathrm{~b}$ ) and molecular analysis of archaeal $16 \mathrm{~S}$ rRNA genes (Fig. 1d): low levels of methane production rates and F430 and no amplification of archaeal 16S rRNA genes were observed within the upper part of turbidites with alternating sand and mud sediment (approximately $80-250 \mathrm{mbsf}$ ). Based on the calculation by Kaneko et al. [29], the measured F430 concentrations were equivalent to approximately $10^{6}-10^{8}$ cells of methanogens per g sediments. These levels of F430 contents were comparable with those at another site of the eastern Nankai Trough and off the Shimokita Peninsula and one or two orders of magnitude lower than those in paddy soils [29].

\section{Archaeal and methanogenic community compositions in sediment core samples}

To evaluate the methanogen diversity in sediment core samples, 454-pyrosequencing analysis of archaeal 16S rRNA genes was performed because in our previous study [24], prokaryotic $16 \mathrm{~S}$ rRNA gene sequence analysis showed that methanogens constituted a major proportion in total archaea but not in total prokaryotes. After quality filtering, pyrosequencing yielded $6857-13,076$ reads per sample. At a cut-off value of $97 \%$ similarity, a total of 2230 OTUs were obtained. The major taxonomic groups ( $>5 \%$ of the total reads in at least one sample) were 'Hadesarchaeota', 'Woesearchaeales', 'Bathyarchaeia', Methanosarcinia, Marine Benthic Group D, Methanomicrobia, Methanobacteria and 'Asgardarchaeota' (Fig. 2a). The 'Asgardarchaeota' sequences were primarily detected in shallower sediment samples (above 43 mbsf). Intriguingly, 36-99\% of the sequences in the class Methanosarcinia were further assigned to 'Syntrophoarchaeaceae', which contains a butane-oxidizing archaeon $\mathrm{Ca}$. 'Syntrophoarchaeum' [42], although nonmethane gaseous hydrocarbons, including butane, were almost absent in the study area [23].

A total of 456 OTUs of the $16 \mathrm{~S}$ rRNA gene sequences belonging to known methanogens were detected in all of the examined sediment core samples and accounted for $0.5-16.6 \%$ of the total archaeal sequences (Fig. 2b). The lowest proportion of methanogenic sequences was found at $1 \mathrm{mbsf}$ and was located above the sulfate-methane transition zone [24]. The sequences of hydrogenotrophic Methanocalculus, Methanoculleus and Methanobacterium were also detected in clone libraries of the methyl-coenzyme $M$ reductase $(m c r A)$ genes [24], which were previously analyzed from the same DNA samples used for the analysis in this study. Consistent with this previous $m c r A$ gene analysis [24] and the present radiotracer activity measurements, hydrogenotrophic methanogens dominated throughout the depths $(62-97 \%$ of the total methanogenic sequences in a sediment sample), followed by methylotrophic methanogens (0-27\%) and acetoclastic methanogens $(0-14 \%)$ (provided that all of the sequences of Methanosarcina are classified into both methylotrophic and acetoclastic groups, and all sequences of Methanofastidiosales are classified into both hydrogenotrophic and methylotrophic groups). Among the methanogenic genera found in this study, only Methanoculleus and Methanosarcina were previously recovered from sediments at hydrate sites in the 16S rRNA gene sequencing analysis [43-45].

\section{Enrichment cultures of methanogens}

Batch-type cultivation was used to obtain viable methanogens from the sediment core samples. After the incubation of 30 sediment slurry samples for up to approximately 2 years, $55 \%(\mathrm{v} / \mathrm{v})$ of the maximum theoretical yield of methane was produced from seven samples supplemented with methylated compounds (i.e., methanol and TMA), whereas methane with an average of $<0.1 \%$ of the maximum theoretical yield was produced from eight cultures supplemented with $\mathrm{H}_{2} / \mathrm{CO}_{2}$ and acetate (Supplementary Table S4). In hydrogen- and acetateamended cultures, the acetate concentration increased together with the depletion of hydrogen after cultivation, suggesting the occurrence of the acetogenic activity. To prevent acetogen growth, the incubation of sediment slurry supplemented with $\mathrm{H}_{2} / \mathrm{CO}_{2}$, acetate and bacteria-specific antibiotics was also performed. However, none of these cultures showed methane production. In contrast, methane production was observed in five culture samples supplemented with methylated compounds and antibiotics (Supplementary Table S4).

\section{Phylogenetic diversity of culturable methanogens}

A total of ten methanogenic isolates were obtained together with nine enrichment culture clones assigned to methanogens (Fig. 3 and Supplementary Table S5). The isolates showed methane production from $\mathrm{H}_{2} / \mathrm{CO}_{2}$, acetate and/or methylated compounds, and the cells showed $\mathrm{F}_{420}$-autofluorescence (Fig. 3). These methanogenic cultures were obtained from various sediment depths. Methylotrophic methanogens were most frequently recovered in terms of sediment sample numbers. Acetoclastic 


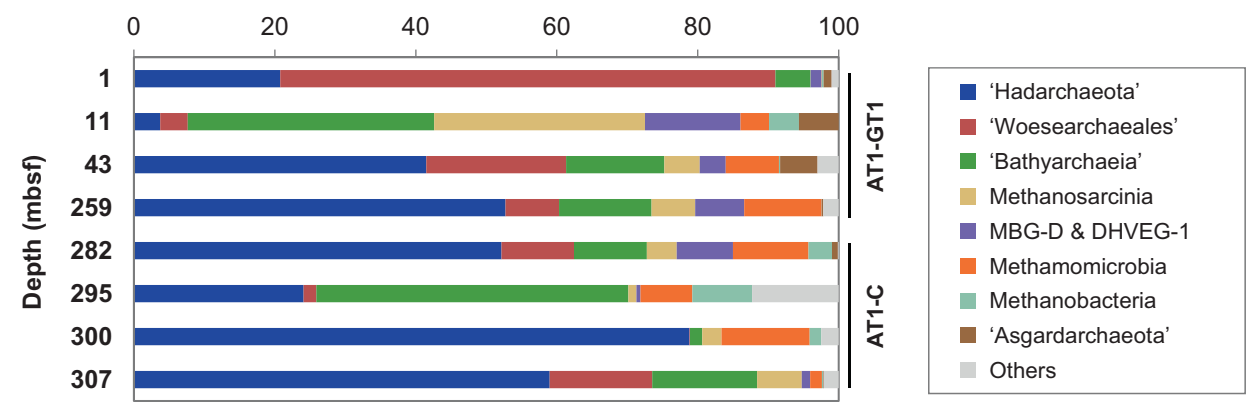

b
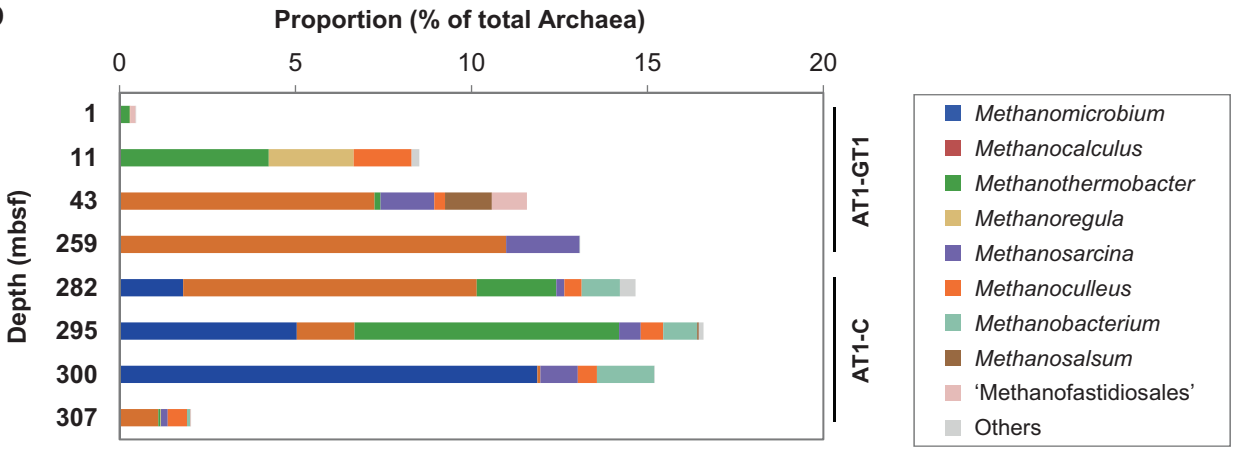

Fig. 2 Archaeal community structures in the studied sites. Community compositions of archaea (a) and methanogens (b) in the sediment core samples based on the archaeal 16S rRNA gene sequences. Taxonomic groups that accounted for $>5 \%$ and $>1 \%$ are indicated in (a) and (b), respectively. DHVEG Deep sea Hydrothermal Vent Euryarchaeotal Group, MBG-D Marine Benthic Group D.

and methylotrophic methanogens, such as Methanosarcina, Methanolobus and Methanosaeta, were not previously isolated from sediments in hydrate areas, although an enrichment culture containing methylotrophic Methanococcoides was previously obtained [12] (Fig. 3). Based on the 16S rRNA gene sequences, the isolates and culture clones were classified into the known methanogenic orders Methanomicrobiales, Methanosarcinales, Methanobacteriales and Methanococcales. The 16S rRNA gene sequences identical or closely related ( $>99 \%$ sequence similarity) to the isolates Methanocalculus sp. $1 \mathrm{H} 1 \mathrm{Hc} 7$, Methanoculleus sp. 25XMc2 and Methanosarcina sp. MSS35 were found in 454pyrosequencing data retrieved directly from the sediments and accounted for $0.08-76.4 \%$ and $0.01-11.2 \%$ of the total methanogenic and archaeal sequences, respectively, in each sediment sample (Supplementary Table S5). The mcrA gene sequences identical to Methanocalculus sp. $1 \mathrm{H} 1 \mathrm{Hc} 7$ and Methanoculleus sp. $25 \mathrm{XMc} 2$, were also found in $\mathrm{mcr} A$ clone libraries retrieved from the same DNA samples in this study [24].

Six out of ten isolates and enrichment culture clones of hydrogenotrophic methanogens were obtained from initial slurry cultures supplemented with methylated compounds and subsequent $\mathrm{H}_{2} / \mathrm{CO}_{2}$-amended cultures (Supplementary Table S5). Only one hydrogenotrophic methanogen, strain $12 \times 3 c 12$, was obtained from the initial slurry culture with $\mathrm{H}_{2} / \mathrm{CO}_{2}$. Some acetogenic bacteria are known to oxidize methanol to $\mathrm{H}_{2} / \mathrm{CO}_{2}$ in coculture with hydrogenotrophic microorganisms [46, 47], suggesting that many of the hydrogenotrophic methanogens isolated or detected in this study grew with syntrophic methanol oxidation in the initial cultures supplemented with methylated compounds. Indeed, bacterial clones solely detected in these cultures were closely related to an acetogenic bacterium, Acetobacterium carbinolicum [48] (99\% sequence similarity in the $16 \mathrm{~S}$ rRNA gene). Accordingly, methanol might be an indirect methanogenic substrate for hydrogenotrophic methanogens, which are utilized by the bacterium to yield hydrogen. Because the $\mathrm{H}_{2}$ partial pressure on syntrophic methanol oxidation was lower than the direct supplementation of $\mathrm{H}_{2}$ under the examined conditions, many hydrogenotrophic methanogens would have been unable to grow in the initial culture when suddenly exposed to a high substrate $\left(\mathrm{H}_{2}\right)$ concentration, as previously suggested [49].

Methanogen isolates were also successfully obtained from the slurry samples initially cultivated without the addition of methanogenic substrates, followed by subculturing with the substrates (Supplementary Table S5). The methanogenic isolates and clones assigned to hydrogenotrophic Methanobacterium and Methanococcus and obligatory acetoclastic Methanosaeta originated only from these cultures.

\section{Methanogenesis from sediment slurries without any supplementation}

The sediment slurry sample from 43 mbsf that showed the highest potential methanogenic activity was incubated without the addition of substrates. Incubation at $25^{\circ} \mathrm{C}$ for 14 months resulted in methane production up to $4.3 \mu \mathrm{mol} \mathrm{g}^{-1}$ sediment (Supplementary Fig. S1).

The slurry sample after 14 months of incubation was subjected to clone library and quantitative PCR analyses based on archaeal $16 \mathrm{~S}$ rRNA genes. Only two archaeal sequences were obtained: the sequences of these clones were identical to those of the isolated strain Methanosarcina sp. MSS35 (42 out of 46 clones) and Methanolobus sp. 17PMc2 (4 clones). Strain MSS35 utilized acetate and methylated compounds, whereas strain 17PMc2 utilized only methylated compounds, suggesting that methane was produced via the methylotrophic pathway or methylotrophic and acetoclastic pathways in the $43 \mathrm{mbsf}$ slurry sample. After incubation, archaeal 16S rRNA gene copy numbers were $2.6 \times 10^{5} \mathrm{~g}^{-1}$ of sediment, which was two orders of magnitude higher than those in the original 43 mbsf sediment sample [24].

Based on porewater chemistry data [24], at the start of this incubation, the slurry sample is estimated to have contained 


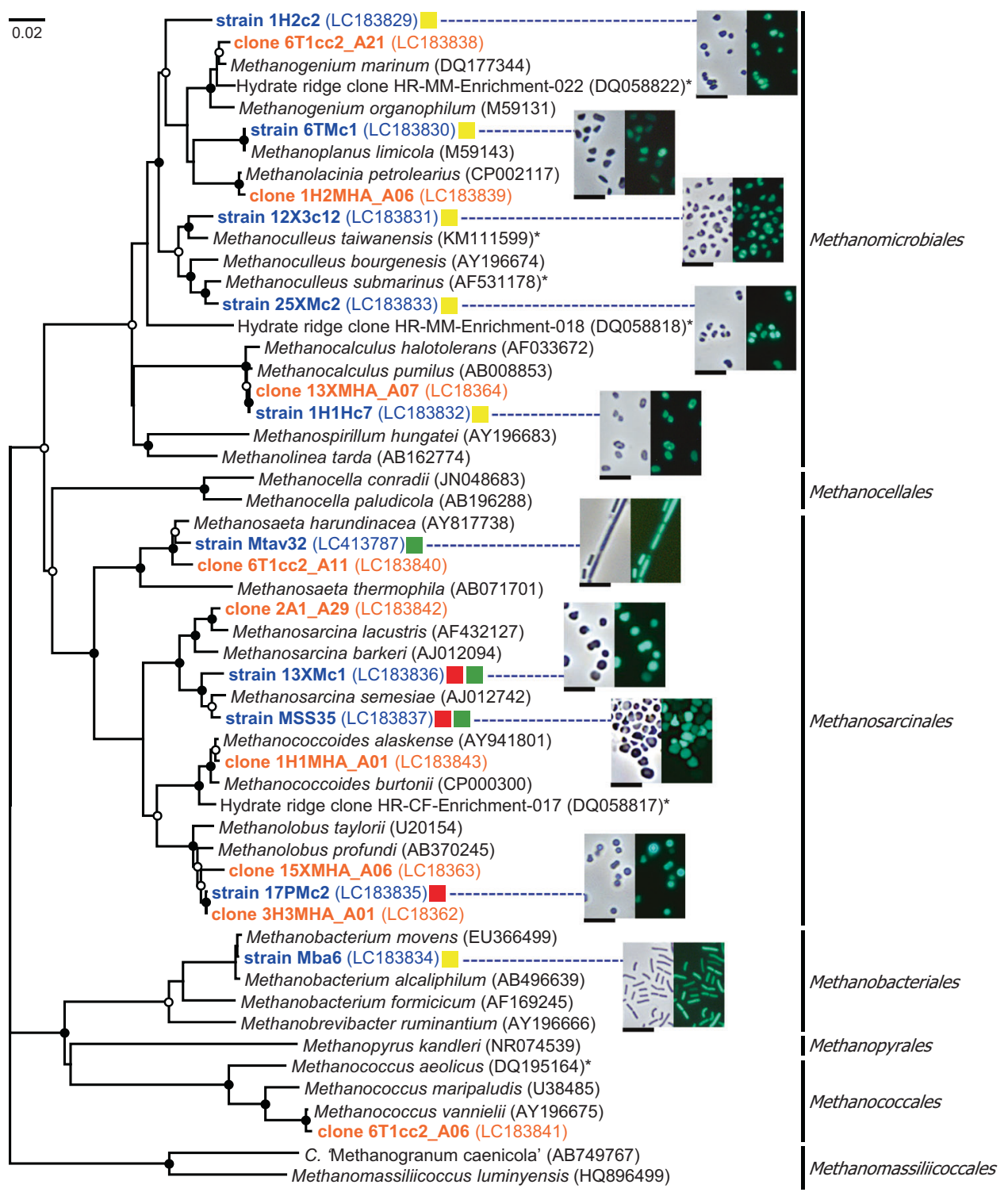

Fig. 3 Neighbour-joining tree showing the diversity of methanogenic isolates (blue) and representative clones in enrichment cultures (orange) based on the 16S rRNA gene sequences and phase-contrast (left) and fluorescence (right) micrographs of the cell morphologies of the isolates. The asterisks indicate the species or clones that were obtained from hydrate-bearing subseafloor sediments in previous studies. The substrate utilization of the isolates is indicated by coloured squares: $\mathrm{H}_{2} / \mathrm{CO}_{2}$ (yellow), methanol (red) and acetate (green). Filled and open circles indicate branches with bootstrap values $>80 \%$ and $>50 \%$, respectively, in both neighbour-joining and maximum-likelihood trees. Bar: 0.02 nucleotide substitutions per position. In micrographs, the bars represent $5 \mu \mathrm{m}$.

approximately $0.02 \mu \mathrm{mol} \mathrm{g}{ }^{-1}$ acetate derived from the sediment porewater. The amount of methane that can theoretically be produced from the conversion of this porewater acetate is much lower than that of actually produced methane. Collectively, these results suggest that the degradation of organic matter coupled to methylotrophic (and acetoclastic) methanogenesis occurred in the long-term batch incubation of the 43 mbsf sediment sample without any substrate supplementation.

\section{Temperature characteristics of methane production in} methanogenic isolates

The methanogenic activity levels at different temperatures, corresponding to different sediment depths, were examined using two methanogenic isolates, Methanocalculus sp. $1 \mathrm{H} 1 \mathrm{Hc} 7$ and Methanoculleus sp. 25XMc2. These two hydrogenotrophic strains were selected because of their predominance and prevalence in the original sediment core samples (Supplementary Table S5).
Both isolates produced methane at $4-55^{\circ} \mathrm{C}$, with the production rate maximized at $40-45^{\circ} \mathrm{C}$ (Fig. 4). Assuming that the geothermal gradient is $0.03^{\circ} \mathrm{C} \mathrm{m}^{-1}$.

in the eastern Nankai Trough [27], this result indicates that these strains have the ability to produce methane at in situ temperatures and is consistent with the depth profiles of ${ }^{14} \mathrm{C}$ tracer activities and F430 concentrations. Similar temperature dependence of the methane production rate has been reported for other hydrogenotrophic methanogens, such as Methanocullues submarinus and Methanococcus aerolicus isolated from the eastern Nankai Trough sediments, although their relative abundances in natural settings have not yet been assessed $[15,17]$.

\section{DISCUSSION}

To estimate the diversity and potential activity of methanogenic microorganisms in the methane hydrate-concentrated zone, 


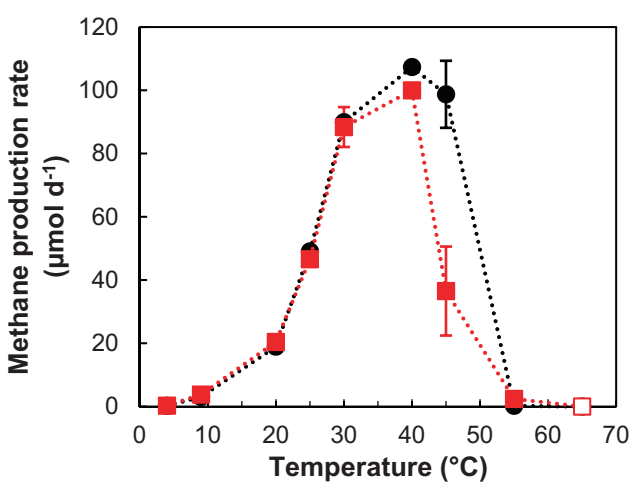

Fig. 4 Temperature dependence of the methane production rate in hydrogenotrophic methanogenic isolates. Open symbols indicate no methane production. Symbols: black circle, Methanocalculus sp. $1 \mathrm{H} 1 \mathrm{Hc} 7$; red square, Methanoculleus sp. 25XMc2.

subseafloor sediment should be collected with caution against contamination from seawater and drilling fluids. This is especially important in this study because contamination control tracers could not be used during coring/sample collection and because the coring methods using extended core barrels are disruptive to the cores. Therefore, we carefully selected core samples to minimize the risk of contamination: X-ray CT scanning was performed immediately after sample collection, and part of the samples showing neither cracks, disturbance, nor traces of drilling fluid was used for further analyses. As a result, all core samples were collected exclusively from mud layers. We further removed the core sample surfaces (approximately $3 \mathrm{~cm}$ thick) and only used the sediments in the centre for all microbiological experiments. In addition, we checked the Illumina 16S rRNA gene sequence data to confirm the absence of sequences assigned to the SAR11 clade and the genus Xanthomonas indicative of contamination from seawater and drilling fluids, respectively [24]. Indeed, no such sequences were detected in the data from all the samples used.

Amplicon sequencing and long-term batch incubation of 30 sediment samples revealed that methanogens in the subseafloor sediment of biogenic gas hydrate deposits are phylogenetically and metabolically more diverse than previously found. The use of indirect methanogenic substrates, which are utilized by bacteria to yield substrates for methanogens, was more effective in culturing methanogens than the use of direct substrates, especially for hydrogenotrophic methanogens. Imachi et al. [50] reported that an initial enrichment culture of subseafloor sediments using a continuous-flow-type cultivation system supplemented with indirect methanogenic substrates resulted in successful culturing of methanogens, whereas the initial cultures using a batch-type system did not. Our results indicated that initially using a batch-type cultivation system supplemented with indirect methanogenic substrates is also effective in culturing methanogens from subseafloor sediments.

The carbon isotopic ratios of methane and DIC suggest that methane in the studied sediments was of a biogenic origin via the carbonate reduction pathway. Both radiotracer experiments and molecular analyses consistently indicated the predominance of hydrogenotrophic methanogenic pathways in the sediments. The predominance of hydrogenotrophic methanogenic activity based on radiotracer experiments was also found in sediments from the Cascadia margin [5] and the central Nankai Trough [51]. This study revealed that two hydrogenotrophic methanogens, Methanocalculus and Methanoculleus, that were dominant in methanogenic communities in sediment samples showed their upper limits for methanogenesis at temperatures of approximately $45-50^{\circ} \mathrm{C}$. This trend is in good agreement with radiotracer experiments in previous studies [7, 51]: potential methanogenic activity in sediments at four sites in the central Nankai Trough markedly decreased at depths corresponding to an estimated temperature of approximately $45^{\circ} \mathrm{C}$. The occurrence of in situ methanogenesis at sediment depths corresponding to these temperatures is among the important targets for future study.

The detection of methanol in sediment porewater, the methylotrophic methanogenic activity from methanol and the culturable obligatory methylotrophic methanogens from various sediment depths and from incubated sediment samples without any supplementation all indicate the potential for methylotrophic methanogenesis. Consistent with our results, previous studies have detected evidence for methylotrophic methanogenesis in deeply buried sediments: conversion of radiolabelled methanol to methane in the sediments from the central Nankai Trough [51] and the Japan Sea [21], transcripts for enzymes involved in methylotrophic methanogenesis in sediment from the Peru Margin sediment [52] and $\mathrm{mcr} A$ gene sequences related to methylotrophic methanogens in sediments off Shimokita Peninsula [14]. Our results further suggest the potential for methylotrophic methanogenesis from methanol in deeply buried sediments. These findings provide insight into subsurface methanogenesis because the occurrence of methylotrophic methanogenesis has focused on the surface [53] but not on deep-buried sediments.

In conclusion, this study reveals the previously overlooked phylogenetic and metabolic diversity of methanogens in subseafloor sediments in biogenic gas hydrate areas. These lines of evidence along with future examinations of the occurrence and in situ activity of methanogens in deeper sediments will provide the vertical profile of methanogenesis, a key issue for understanding marine gas hydrate formation.

\section{REFERENCES}

1. Macdonald IR, Guinasso NL, Sassen R, Brooks JM, Lee L, Scott KT. Gas hydrate that breaches the sea-floor on the continental-slope of the Gulf-of-Mexico. Geology. 1994;22:699-702.

2. Kvenvolden KA. A review of the geochemistry of methane in natural gas hydrate. Org Geochem. 1995;23:997-1008.

3. Milkov AV. Molecular and stable isotope compositions of natural gas hydrates: a revised global dataset and basic interpretations in the context of geological settings. Org Geochem. 2005;36:681-702.

4. Cragg BA, Parkes RJ, Fry JC, Weightman AJ, Rochelle PA, Maxwell JR. Bacterial populations and processes in sediments containing gas hydrates (ODP Leg 146: Cascadia Margin). Earth Planet Sc Lett. 1996;139:497-507.

5. Yoshioka H, Maruyama A, Nakamura T, Higashi Y, Fuse H, Sakata S, et al. Activities and distribution of methanogenic and methane-oxidizing microbes in marine sediments from the Cascadia Margin. Geobiology. 2010;8:223-33.

6. Yoshioka H, Sakata S, Cragg BA, Parkes RJ, Fujii T. Microbial methane production rates in gas hydrate-bearing sediments from the eastern Nankai Trough, off central Japan. Geochem J. 2009;43:315-21.

7. Heuer VB, Inagaki F, Morono Y, Kubo Y, Spivack AJ, Viehweger B, et al. Temperature limits to deep subseafloor life in the Nankai Trough subduction zone. Science. 2020;370:1230-4.

8. Wellsbury P, Goodman K, Cragg BA, Parkes RJ. The geomicrobiology of deep marine sediments from Blake Ridge containing methane hydrate (sites 994, 995 and 997). Proc Ocean Drill Program Sci results. 2000;164:379-91.

9. Bidle KA, Kastner M, Bartlett DH. A phylogenetic analysis of microbial communities associated with methane hydrate containing marine fluids and sediments in the Cascadia margin (ODP site 892B). Fems Microbiol Lett. 1999;177:101-8.

10. Reed DW, Fujita Y, Delwiche ME, Blackwelder DB, Sheridan PP, Uchida T, et al. Microbial communities from methane hydrate-bearing deep marine sediments in a forearc basin. Appl Environ Microbiol. 2002;68:3759-70.

11. Briggs $B R$, Inagaki $F$, Morono $Y$, Futagami $T$, Huguet $C$, Rosell-Mele $A$, et al. Bacterial dominance in subseafloor sediments characterized by methane hydrates. FEMS Microbiol Ecol. 2012;81:88-98.

12. Kendall MM, Boone DR. Cultivation of methanogens from shallow marine sediments at Hydrate Ridge, Oregon. Archaea. 2006;2:31-38.

13. Fry JC, Parkes RJ, Cragg BA, Weightman AJ, Webster G. Prokaryotic biodiversity and activity in the deep subseafloor biosphere. FEMS Microbiol Ecol. 2008; 66:181-96.

14. Nunoura T, Takaki Y, Shimamura S, Kakuta J, Kazama H, Hirai M, et al. Variance and potential niche separation of microbial communities in subseafloor sediments off Shimokita Peninsula, Japan. Environ Microbiol. 2016;18:1889-906. 
15. Mikucki JA, Liu Y, Delwiche M, Colwell FS, Boone DR. Isolation of a methanogen from deep marine sediments that contain methane hydrates, and description of Methanoculleus submarinus sp. nov. Appl Environ Microbiol. 2003;69:3311-6.

16. Weng $C-Y$, Chen S-C, Lai M-C, Wu S-Y, Lin S, Yang TF, et al. Methanoculleus taiwanensis sp. nov., a methanogen isolated from deep marine sediment at the deformation front area near Taiwan. Int J Syst Evol Micr. 2015;65:1044-9.

17. Kendall MM, Liu Y, Sieprawska-Lupa M, Stetter KO, Whitman WB, Boone DR. Methanococcus aeolicus sp. nov., a mesophilic, methanogenic archaeon from shallow and deep marine sediments. Int J Syst Evol Microbiol. 2006;56:1525-9.

18. Strąpoć D, Ashby M, Wood L, Levinson R, Huizinga B. Significant contribution of methyl/methanol-utilising methanogenic pathway in a subsurface biogas environment. In: Skovhus T, Whitby C, editors. Applied microbiology and molecular biology in oilfield systems. Dordrecht: Springer; 2010. p. 211-6.

19. Guo H, Liu R, Yu Z, Zhang H, Yun J, Li Y, et al. Pyrosequencing reveals the dominance of methylotrophic methanogenesis in a coal bed methane reservoir associated with Eastern Ordos Basin in China. Int J Coal Geol. 2012;93:56-61.

20. Katayama T, Yoshioka H, Muramoto Y, Usami J, Fujiwara K, Yoshida S, et al. Physicochemical impacts associated with natural gas development on methanogenesis in deep sand aquifers. ISME J. 2015;9:436-46.

21. Yanagawa K, Tani A, Yamamoto N, Hachikubo A, Kano A, Matsumoto R, et al. Biogeochemical cycle of methanol in anoxic deep-sea sediments. Microbes Environ. 2016;31:190-3.

22. Colwell F, Matsumoto R, Reed D. A review of the gas hydrates, geology, and biology of the Nankai Trough. Chem Geol. 2004;205:391-404.

23. Uchida T, Waseda A, Namikawa T. Methane accumulation and high concentration of gas hydrate in marine and terrestrial sandy sediments. In: Collett T, Johnson A Knapp C, Boswell R, editors. Natural gas hydrates: energy resource potential and associated geologic hazards. Tulsa: American Association of Petroleum Geologists Memoir 89; 2009. p. 401-13.

24. Katayama T, Yoshioka H, Takahashi HA, Amo M, Fujii T, Sakata S. Changes in microbial communities associated with gas hydrates in subseafloor sediments from the Nankai Trough. FEMS Microbiol Ecol. 2016;92:fiw093.

25. Oba M, Sakata S, Fujii T. Archaeal polar lipids in subseafloor sediments from the Nankai Trough: Implications for the distribution of methanogens in the deep marine subsurface. Org Geochem. 2015;78:153-60.

26. Noguchi S, Shimoda N, Takano O, Oikawa N, Inamori T, Saeki T, et al. 3-D internal architecture of methane hydrate-bearing turbidite channels in the eastern Nankai Trough, Japan. Mar Pet Geol. 2011;28:1817-28.

27. Fujii T, Suzuki K, Takayama T, Tamaki M, Komatsu Y, Konno Y, et al. Geological setting and characterization of a methane hydrate reservoir distributed at the first offshore production test site on the Daini-Atsumi Knoll in the eastern Nankai Trough, Japan. Mar Pet Geol. 2015;66:310-22.

28. Kanno T, Fukuhara M, Osawa O, Chee S, Takekoshi M, Wang X, et al. Estimation of geothermal gradient in marine gas-hydrate-bearing formation in the Eastern Nankai Trough. Beijing, China: Proceedings of the 8th International Conference on Gas Hydrates (ICGH8-2014); 2014.

29. Kaneko M, Takano Y, Ogawa NO, Sato Y, Yoshida N, Ohkouchi N. Estimation of methanogenesis by quantification of coenzyme $F 430$ in marine sediments. Geochem J. 2016:50:453-60.

30. Kaneko M, Takano Y, Chikaraishi Y, Ogawa NO, Asakawa S, Watanabe T, et al. Quantitative analysis of coenzyme F430 in environmental samples: a new diagnostic tool for methanogenesis and anaerobic methane oxidation. Anal Chem. 2014;86:3633-8.

31. Katayama T, Kamagata $Y$ Cultivation of Methanogens. Hydrocarbon and lipid microbiology protocols. In: McGenity T, Timmis K, Nogales B, editors. Springer protocols handbooks. Berlin, Heidelberg: Springer; 2016. p. 177-95.

32. Schloss PD, Westcott SL, Ryabin T, Hall JR, Hartmann M, Hollister EB, et al. Introducing mothur: open-source, platform-independent, community-supported software for describing and comparing microbial communities. Appl Environ Microbiol. 2009;75:7537-41.

33. Pruesse E, Quast C, Knittel K, Fuchs BM, Ludwig W, Peplies J, et al. SILVA: a comprehensive online resource for quality checked and aligned ribosomal RNA sequence data compatible with ARB. Nucleic Acids Res. 2007;35:7188-96.

34. Tamura K, Peterson D, Peterson N, Stecher G, Nei M, Kumar S. MEGA5: molecular evolutionary genetics analysis using maximum likelihood, evolutionary distance, and maximum parsimony methods. Mol Biol Evol. 2011;28:2731-9.

35. Jobb G, von Haeseler A, Strimmer K. TREEFINDER: a powerful graphical analysis environment for molecular phylogenetics. BMC Evol Biol. 2004;4:18.

36. Whiticar MJ. Carbon and hydrogen isotope systematics of bacterial formation and oxidation of methane. Chem Geol. 1999;161:291-314.

37. Scheller S, Goenrich M, Thauer RK, Jaun B. Methyl-coenzyme M reductase from methanogenic archaea: Isotope effects on the formation and anaerobic oxidation of methane. J Am Chem Soc. 2013;135:14975-84.
38. Diekert G, Konheiser U, Piechulla K, Thauer RK. Nickel requirement and factor F430 content of methanogenic bacteria. J Bacteriol. 1981;148:459-64.

39. Mayr S, Latkoczy C, Krüger M, Günther D, Shima S, Thauer RK, et al. Structure of an F430 variant from archaea associated with anaerobic oxidation of methane. J Am Chem Soc. 2008;130:10758-67.

40. House CH, Orphan VJ, Turk KA, Thomas B, Pernthaler A, Vrentas JM, et al. Extensive carbon isotopic heterogeneity among methane seep microbiota. Environ Microbiol. 2009;11:2207-15.

41. Lloyd KG, Alperin MJ, Teske A. Environmental evidence for net methane production and oxidation in putative ANaerobic MEthanotrophic (ANME) archaea. Environ Microbiol. 2011;13:2548-64.

42. Laso-Pérez R, Wegener G, Knittel K, Widdel F, Harding KJ, Krukenberg V, et al. Thermophilic archaea activate butane via alkyl-coenzyme $M$ formation. Nature. 2016;539:396-401.

43. Inagaki F, Nunoura T, Nakagawa S, Teske A, Lever M, Lauer A, et al. Biogeographical distribution and diversity of microbes in methane hydrate-bearing deep marine sediments on the Pacific Ocean Margin. Proc Natl Acad Sci USA. 2006;103:2815-20.

44. Marchesi JR, Weightman AJ, Cragg BA, Parkes RJ, Fry JC. Methanogen and bacterial diversity and distribution in deep gas hydrate sediments from the Cascadia Margin as revealed by $16 \mathrm{~S}$ rRNA molecular analysis. FEMS Microbiol Ecol. 2001;34:221-8.

45. Nunoura T, Inagaki F, Delwiche ME, Colwell FS, Takai K. Subseafloor microbial communities in methane hydrate-bearing sediment at two distinct locations (ODP Leg 204) in the Cascadia Margin. Microbes Environ. 2008;23:317-25.

46. Cord-Ruwisch R, Ollivier B. Interspecific hydrogen transfer during methanol degradation by Sporomusa acidovorans and hydrogenophilic anaerobes. Arch Microbiol. 1986;144:163-5.

47. Heijthuijsen JHFG, Hansen TA. Interspecies hydrogen transfer in co-cultures of methanol-utilizing acidogens and sulfate-reducing or methanogenic bacteria. FEMS Microbiol Ecol. 1986;2:57-64.

48. Eichler B, Schink B. Oxidation of primary aliphatic alcohols by Acetobacterium carbinolicum sp. nov., a homoacetogenic anaerobe. Arch Microbiol. 1984;140: 147-52.

49. Parkes RJ, Cragg B, Roussel E, Webster G, Weightman A, Sass H. A review of prokaryotic populations and processes in sub-seafloor sediments, including biosphere: geosphere interactions. Mar Geol. 2014;352:409-25.

50. Imachi H, Aoi K, Tasumi E, Saito Y, Yamanaka Y, Saito Y, et al. Cultivation of methanogenic community from subseafloor sediments using a continuous-flow bioreactor. ISME J. 2011;5:1913-25.

51. Newberry CJ, Webster G, Cragg BA, Parkes RJ, Weightman AJ, Fry JC. Diversity of prokaryotes and methanogenesis in deep subsurface sediments from the Nankai Trough, Ocean Drilling Program Leg 190. Environ Microbiol. 2004;6:274-87.

52. Orsi WD, Edgcomb VP, Christman GD, Biddle JF. Gene expression in the deep biosphere. Nature 2013;499:205-8.

53. Vigneron A, L'Haridon S, Godfroy A, Roussel EG, Cragg BA, Parkes RJ, et al. Evidence of active methanogen communities in shallow sediments of the sonora margin cold seeps. Appl Environ Microbiol. 2015;81:3451-9.

\section{ACKNOWLEDGEMENTS}

This study was part of the Research Consortium for Methane Hydrate Resources in Japan (MH21) funded by the Ministry of Economy, Trade and Industry (METI). This study was financially supported in part by JSPS KAKENHI Grant Numbers JP15H05332, JP17K15183, JP18H05295 and JP19H04261. The authors thank the crew of the D/N Chikyu for assisting with the sediment sample collection. The authors thank Aung Than Tin and Toshinori Imai for their valuable discussion. Thanks are further extended to Yoichi Kamagata for his valuable comments that greatly improved our manuscript. The authors also thank Chiwaka Miyako, Fumie Nozawa and Kuniko Syuin for their assistance with the molecular analysis and cultivation experiments.

\section{AUTHOR CONTRIBUTIONS}

TK, HY and SS designed the study. TK, HY, MA and TF collected the samples. TK performed molecular analyses. TK and HY performed enrichment cultures, and TK isolated methanogens. HY performed geochemical analysis together with HAT. HY and SY performed radiotracer experiments. KM performed F430 analyses. TK wrote the manuscript together with HY and SS, with comments and suggestions from all other authors.

\section{COMPETING INTERESTS}

The authors declare no competing interests. 


\section{ADDITIONAL INFORMATION}

Supplementary information The online version contains supplementary material available at https://doi.org/10.1038/s41396-021-01175-7.

Correspondence and requests for materials should be addressed to Hideyoshi Yoshioka.

Reprints and permission information is available at http://www.nature.com/ reprints

Publisher's note Springer Nature remains neutral with regard to jurisdictional claims in published maps and institutional affiliations.
Open Access This article is licensed under a Creative Commons Attribution 4.0 International License, which permits use, sharing, adaptation, distribution and reproduction in any medium or format, as long as you give appropriate credit to the original author(s) and the source, provide a link to the Creative Commons license, and indicate if changes were made. The images or other third party material in this article are included in the article's Creative Commons license, unless indicated otherwise in a credit line to the material. If material is not included in the article's Creative Commons license and your intended use is not permitted by statutory regulation or exceeds the permitted use, you will need to obtain permission directly from the copyright holder. To view a copy of this license, visit http://creativecommons.org/licenses/by/4.0/.

(c) The Author(s) 2021 